\title{
REACH: Its Potential Implications for the Insurance Industry
}

\author{
Christine Blach, Jürg Schmid, and Karl Strässle*
}

\begin{abstract}
The REACH (Registration, Evaluation, Authorization on Chemicals) regulation will primarily affect the chemical industry, but it will also have an impact on industries that process chemicals, and also on the insurance industry. Of the risks a company faces some are managed within the company, whereas others are transferred to insurance companies. REACH may now change the overall risk potential of a company and, as a consequence, this change may alter the portion of risk that is transferred to an insurer. REACH may lead to the identification of so far unknown hazardous properties of chemical substances. Such new findings would increase the risk potential for all companies handling these substances and they could be the basis for new law suits. This could lead to additional exposure for the insurance industry, particularly with respect to liability. In the long run, however, REACH should lead to safer products and, as a consequence, also to a reduction in the number of insurance claims and law suits. Therefore, any kind of risk reduction is to be welcomed by all stakeholders.
\end{abstract}

Keywords: Chemical products · Environment · Health · Insurance $\cdot$ Law suits $\cdot$ Liability $\cdot$ REACH

\section{Introduction}

In November 2005 the European Parliament passed the new legislation on Registration, Evaluation and Authorization on Chemicals (REACH). It is expected that this legislation will come into force in 2007 or 2008. This regulation will require that all chemicals produced or imported in quantities of more than one tonne per year have to be tested for their health and environmental hazards. Tests are required only for single substances, not for mixtures, and some categories of substances are exempt from the regulation.

\section{Goals of REACH}

REACH will close a gap in the EU's regulatory regime for chemicals. It will replace more than 40 existing regulations presently controlling the use and trading of chemical substances. Whereas new substances marketed after 1981 have been subject to a rigorous authorization process, the majority of chemicals, i.e. all that were already on the market before 1981, did not have to pass these safety tests. Chemicals considered of very high concern by the Agency will be subject to an authorization procedure and substances judged to have unacceptable risks may be banned.

Today, existing chemicals are presumed safe until particular hazards are identified With the new regulation, manufacturers within the EU and importers into the EU will have to provide information concerning the risks of their substances and on risk reduction measures to ensure their safe use.

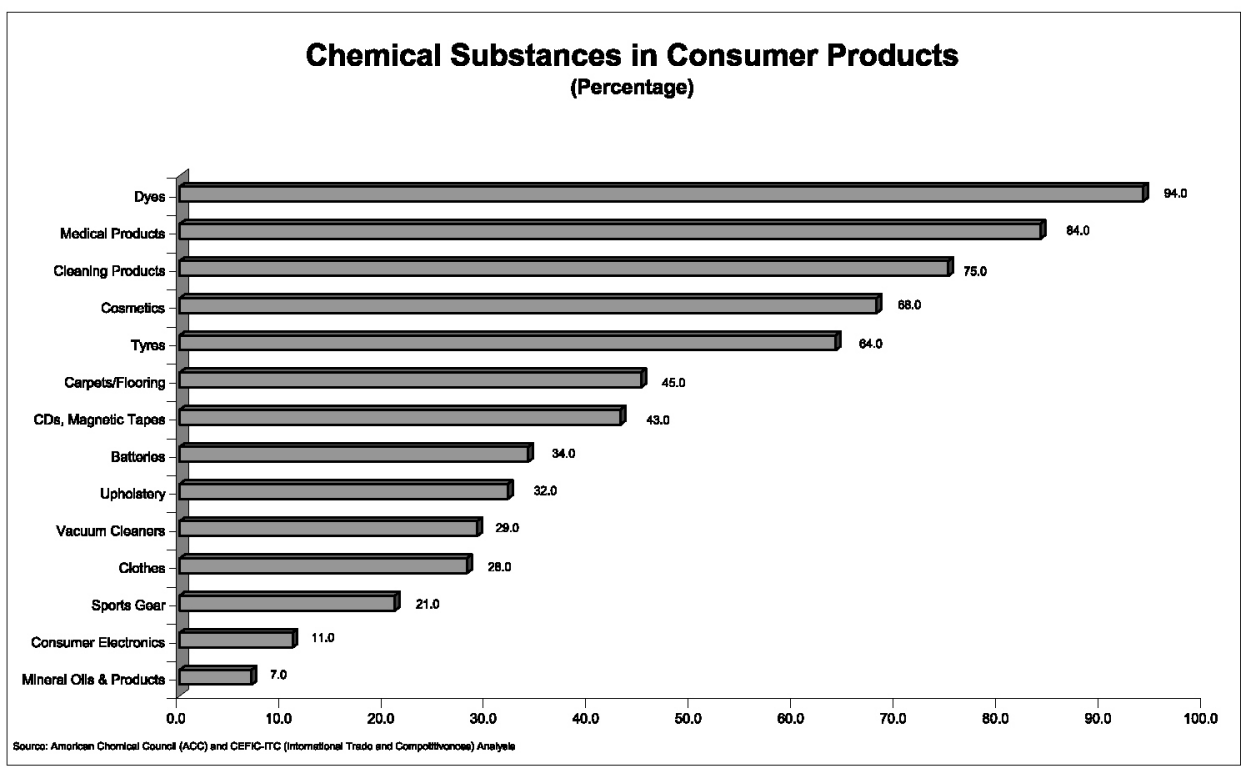

Fig. 1. Chemical substances in consumer products 


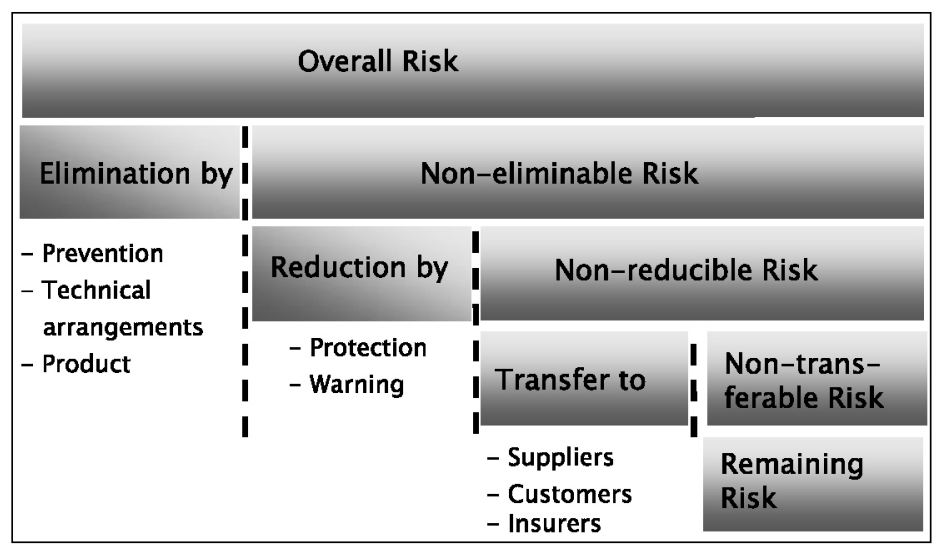

Fig. 2. Risk minimization. Generic concept of risk minimization for any type of company. Part of the non-reducible risk can be transferred to insurance companies.

\section{Consequences of REACH}

REACH will affect the chemical industry since the producer has to provide the required information. To a lesser extent also industries that utilize the goods produced by the chemical industry for the manufacturing of consumer products are involved. To illustrate these implications, Fig. 1 shows the percentage of chemicals used in the manufacturing of consumer goods. In these industries REACH will also raise the awareness for the hazards of the materials that are used.

\section{Risk Transfer from Chemical Industry to Insurance Industry}

Minimizing the risks for safety, health and environment are goals every company should have. Of all industries, the chemical industry has rather high inherent risks. Therefore it has always been under scrutiny by population, media and legislation. Over time, elaborate control systems and regulations were developed by the chemical industry together with governments, industry organizations and standard institutes to eliminate, contain or reduce these risks. Examples for these efforts, among others, are the Responsible Care Programs. However, certain risks still remain and some of them can be transferred to insurance companies (Fig. 2).

How much of the risk can or will be transferred depends on various factors. The most important ones are the risk management philosophy and strategy of a company, its financial capabilities and its readiness to buy insurance, but also the general legal and business environment and the availability of adequate insurance solutions play a role. To enable a risk transfer from the chemical (manufacturing) industry to the insurance industry, insurance companies developed an array of solutions. Assets like the reputation of a company, its market position and its goodwill, however, are usually not insurable. The most common lines of business for which insurance companies provide coverage are:

\section{Property Damage and Business \\ Interruption}

Provides coverage for incidents where property of a company was damaged by fire/explosion or natural hazards and for the financial loss resulting from an interruption of the production as a consequence.

\section{Liability}

Provides coverage for incidents related to a product the company is producing and marketing (product liability), incidents that harm people (general liability and workers' compensation) and incidents that have an impact on the environment (environmental liability).

During the last years, new research findings have raised concerns about a whole array of substances which were either used in the past without much worries about their already known hazardous properties or where new hazards were identified by more sophisticated analytical methods, new research approaches or incidentally. Examples for these developments would be the recent identification of diacetyl as a source of occupational diseases, the pollution of soil and groundwater by chlorinated solvents or polychlorinated biphenyls (PCB), and the pollution of groundwater by hexavalent chromium in Hinckley, California by Pacific Gas \& Electric (PG\&E). This case gained worldwide attention by the movie Erin Brockovich with Julia Roberts. The law suit against Pacific Gas \& Electric (Anderson v. PG\&E) in 1993 was finally settled out of court at a sum of USD 333'000'000. At that point in time (1996), this settlement was the highest ever agreed upon in the USA. However, many settlements reach amounts of several millions of dollars, because in most cases a number of claimants are affected.

\section{Marine (i.e. Transportation)}

Provides coverage for incidents while goods are moved from one location to another.

\section{Impacts REACH May Have on the Insurance Industry}

Because REACH will influence the overall risk of companies in the chemical industry it will probably also have an impact on the insurance industry that will be different for the various lines of business.

\section{Property Damage and Business Interruption}

REACH will probably have only little effect on these types of coverage. The obligation to replace hazardous substances by safer ones might create new potentials for incidents, when for example well understood and monitored production processes have to be changed. New exposures could also be generated by the outsourcing of manufacturing processes to companies into countries which are not subject to the REACH regulation. However, it will be difficult to distinguish whether such an exposure is the result of the introduction of REACH or one of the general trends to outsourcing.

\section{Liability}

Most likely, REACH will have a much larger influence on the different types of liability coverage whereby the short-term effects will be significantly different from the long-term effects. REACH may reveal that substances previously considered safe bear hazards for health or environment. For previously unexplained cases of health impairment or environmental impacts new cause-effect relationships might be established. Since these hazards were not known in the past, also no or insufficient precautionary measures were taken and this might now trigger law suits, mainly related to the lines of workers' compensation, product liability and environmental liability. In such cases the insurance industry will be confronted with defense costs, no matter if the law suits are justified or not.

Long-term it can be expected that REACH will have positive effects for all stakeholders since the risk potential of many more substances will be known in much greater detail. This knowledge will be beneficial for both the chemical industry and the insurance industry, and consumers will benefit as well. The data generated by REACH will support the risk assessment of products exactly in that phase of the product life cycle where it is most cost efficient, i.e. in the conceptual and planning phase (Fig. 3). 
Over time it is possible that the additional knowledge about the risk potential of existing products will lead to a substitution or elimination of products with an unfavorable risk profile for health and/or environment, and they will disappear from the market.

\section{Marine}

If at all, REACH will have only a small impact on this line of business.

\section{Conclusions}

In our view, the insurance industry, together with all the other stakeholders, can benefit from the REACH initiative. Although initially a number of law suits might be filed, it can be expected that the exposure of the insurance industry will be reduced in the long run. REACH will lead to a better understanding of the harmful effects of substances and as a consequence measures can be taken to reduce the exposure for human health and the environment.

Received: August 14, 2006

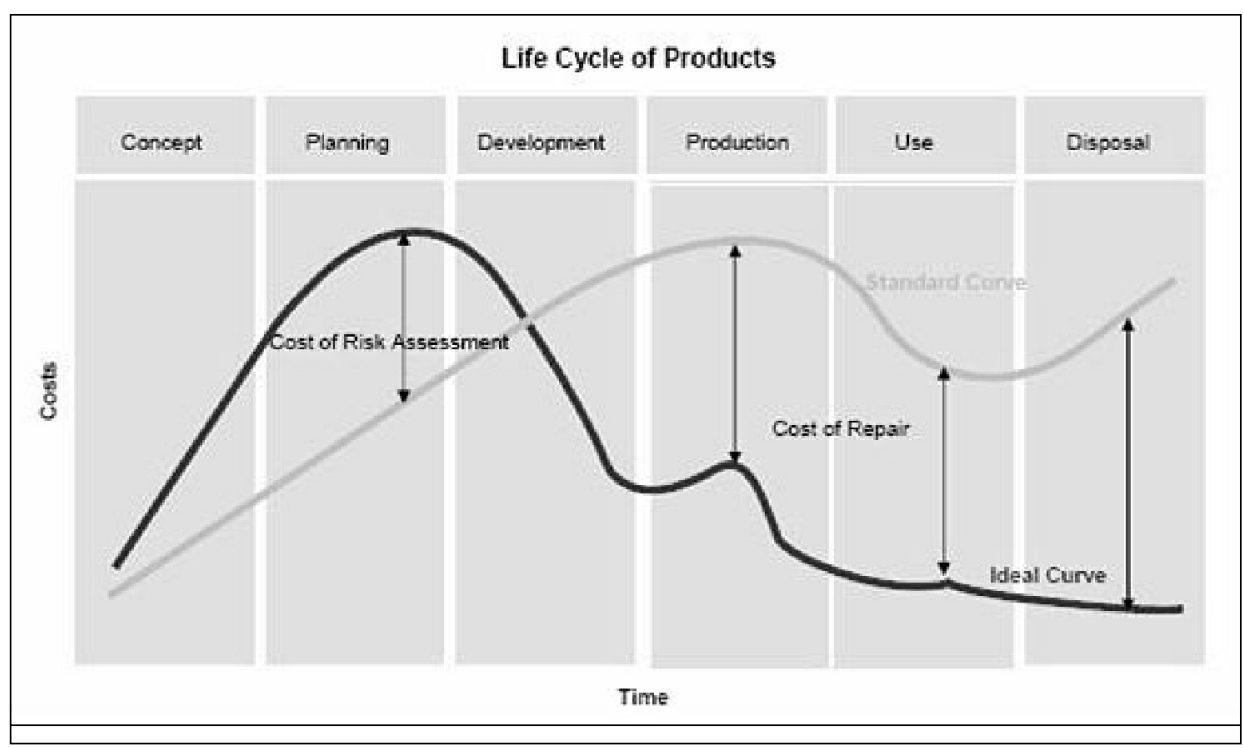

Fig. 3. Risk assessments during the life cycle of products. The earlier within the life cycle of a product the risk assessment is performed the lower are the overall costs. 